\title{
Irrigação suplementar no ciclo do milho "safrinha" sob plantio direto ${ }^{1}$
}

\author{
Alexander B. Pegorare ${ }^{2}$, Euclides Fedatto ${ }^{3}$, Silvio B. Pereira ${ }^{3}$, Luiz C. F. Souza ${ }^{3} \&$ Carlos R. Fietz ${ }^{4}$
}

\begin{abstract}
RESUMO
Propõe-se, neste trabalho, avaliar diferentes lâminas de água aplicadas como irrigação suplementar no ciclo do milho safrinha, sob plantio direto, sua influência na fisiologia, produtividade e viabilidade econômica na região de Dourados, MS. O trabalho foi conduzido na Faculdade de Ciências Agrárias da Universidade Federal da Grande Dourados, UFGD, no período de março a setembro de 2005. Para a análise dos dados foram determinadas as seguintes características fisiológicas: área foliar, altura de inserção de espiga, altura da planta, massa seca da espiga, massa seca total e massa de 100 grãos. A produtividade de grãos foi definida corrigindo-se a umidade para $13 \%$. Os tratamentos com irrigação suplementar foram de 160, 360, 410 e $510 \mathrm{~mm}$. No cálculo de viabilidade econômica utilizaram-se os índices financeiros para o custo de produção do milho safrinha de 2005 e as tarifas de energia homologadas na ANEEL $n^{0} 74$, cujos resultados permitiram as seguintes conclusões: 0 incremento das lâminas aplicadas acarretou aumentos lineares na fisiologia da planta; a irrigação suplementar foi essencial para aumentar a produtividade do milho safrinha e a maior produtividade do milho safrinha não se converteu em maior renda líquida.
\end{abstract}

Palavras-chave: deficiências hídricas, cultura, evapotranspiração

\section{Supplemental irrigation in the cycle of "safrinha" corn under no-tillage system}

\begin{abstract}
The objective of this study was to evaluate different water depths applied as supplemental irrigation in the cycle of "safrinha" corn under no-tillage systems, and their influence on the physiology, productivity and economical viability in the area of Dourados, MS. The work was accomplished in the Experimental Nucleus of Agrarian Sciences in Great Dourados Region, UFGD, in the period from March to September, 2005. For the analysis of the data the following physiologic characteristics were determined: leaf area, height of ear insertion, plant height, ear dry matter, total dry matter and mass of 100 grains. The productivity of grains was determined correcting the water content for $13 \%$. The treatments with supplemental irrigation were of $160,360,410$ and $510 \mathrm{~mm}$. In the calculation of economical viability, the financial indexes were used for the cost of production of the "safrinha" corn in 2005, and the tariffs of energy ratified in the ANEEL $n^{\circ} 74$. The results lead to the following conclusions: the increment of the applied water depths promoted linear increases in the physiology of the plant; the supplemental irrigation was essential to increase the productivity of the "safrinha" corn; and the largest productivity of the "safrinha" corn did not result in greater net income.
\end{abstract}

Key words: water deficits, crop, evapotranspiration

1 Parte da Dissertação de Mestrado do primeiro autor, apresentada à UFGD

2 UEMS, CEP 79260-000, Aquidauana, MS. Fone: (67) 3411-3854. E-mail: alexpegorare@uems.br

3 FCA/UFGD, CEP 79804-970, Dourados, MS. Fone: (67) 3411-3854. E-mail: efedatto@ufgd.edu.br, sbueno@ufgd.edu.br, Icfsouza@ufgd.edu.br

${ }^{4}$ Embrapa Agropecuária Oeste, CEP 79804-970, Dourados, MS. Fone: (67) 3425-5122. E-mail: fietz@cpao.embrapa.br 


\section{INTRODUÇÃO}

A cultura do milho (Zea mays L.) assume importante papel socioeconômico entre as culturas de interesse econômico no Brasil, em virtude de se constituir em matéria-prima impulsionadora de diversos complexos agroindustriais; atualmente, o grande desafio está em se alcançar maior produtividade, diminuindo os custos de produção por meio da incorporação de novas tecnologias no manejo, como irrigação e plantio direto.

No Brasil, o milho sempre foi cultura típica de sequeiro, porém, com a expansão da fronteira agrícola para a região dos Cerrados, o crescimento das áreas plantadas com milho se expandiu; nessas áreas, predominantemente em propriedades médias e grandes, a cultura foi implementada com nível tecnológico mais elevado; a região dos Cerrados, no entanto, apresenta características climáticas bem distintas das regiões originalmente cultivadas, com precipitação média anual menor e chuvas que se concentram no período de novembro a março, com ocorrência de longos períodos de estiagem (Resende et al., 2000); além disso, os solos na região dos cerrados se caracterizam por apresentar baixos teores de nutrientes e armazenamento de água para as plantas (Lopes, 1983); assim, a ocorrência freqüente de "veranicos" tem ocasionado perdas significativas no rendimento das culturas, especialmente quando a falta de água ocorre nos períodos críticos de desenvolvimento da planta (Goedert et al., 1980).

O milho é uma cultura que, sob déficits hídricos causados pelas variações climáticas, obtém respostas diferentes de produtividade podendo ser maior ou menor, de acordo com a época e intensidade do déficit (Cunha \& Bergamaschi, 1992). Normalmente é cultivado em regiões cuja precipitação varia de 300 a 5000 mm anuais, cuja média de água consumida durante o ciclo é de $600 \mathrm{~mm}$. De acordo com Doorenbos \& Kassan (1994), o milho de ciclo médio requer 500 a 800 mm de água, dependendo do clima, para uma boa produção. Swan (1977), analisando os resultados obtidos por diferentes autores, verificou que o consumo de água do milho variou de 410 a $610 \mathrm{~mm}$. Fancelli (1991) relata uma exigência mínima de 300 a 350 mm de água para uma produção satisfatória sem uso de irrigação, porém, essa quantidade deve ser bem distribuída durante o ciclo da cultura.

Henckel (1964) afirmou que se houver deficiência hídrica uma semana após a emissão das anteras, pode ocorrer queda de $50 \%$ na produção; deficiências posteriores resultarão em danos da ordem de 25 a 30\%; de acordo com Aldrich et al. (1982) dois dias de estresse hídrico no florescimento diminui o rendimento em mais de $20 \%$ e, de quatro a oito dias, em mais de $50 \%$.

Considerando o controle do manejo da irrigação via tensiômetro, cada cultura apresenta uma tensão correspondente à sua umidade crítica, a qual depende da cultura e não do solo; no caso da cultura do milho a umidade crítica corresponde a tensão de -0,050 MPa; normalmente define-se que a água está na capacidade de campo do solo quando se encontra retida a tensão de $-0,010 \mathrm{MPa}$ e, no ponto de murcha, quando a tensão é de -15 MPa (Bernardo, 1997).
No final da década de 1970 e na década de 1980, foi grande o crescimento das áreas irrigadas por aspersão convencional e pivô central na região dos Cerrados, através de programas de incentivo à irrigação, haja vista que a cultura do milho passou a ser uma alternativa nos sistemas de produção de grãos e hortaliças, em sucessão e rotação com outras culturas.

Segundo a CONAB (2005), o milho safrinha ocupou uma área correspondente a $21,5 \%$ da área plantada durante a safra de verão, com produção de $21,1 \%$ da safra de verão, representando 17,4\% da produção total de milho. Nos Estados de Mato Grosso do Sul e Mato Grosso, a área com milho safrinha foi, no ano de 2004, maior que a do plantio de verão, informações que vêm confirmar que esta cultura tem papel de destaque na agricultura brasileira causando, inclusive, impacto no mercado interno, porém é uma cultura de elevado risco, o que se deve principalmente à variabilidade de épocas de plantio e, conseqüentemente, à irregularidade e às adversidades climáticas, sobretudo no que se refere ao déficit hídrico (Tsunechiro \& Miele, 1999).

Para se obter maior rendimento agrícola e aumento da competitividade do milho produzido no Brasil, o ajuste de sistemas de produção é extremamente necessário de forma a atender diferentes condições produtivas e uso; portanto, o conhecimento do efeito de diferentes lâminas aplicadas como irrigação suplementar na cultura do milho torna-se fator significativo para a tomada de decisões dentro do sistema de manejo agrícola. Com base neste enfoque se propõe, com o presente trabalho, avaliar diferentes lâminas de água aplicadas como irrigação suplementar no ciclo do milho safrinha sob plantio direto, sua influência na fisiologia, produtividade e viabilidade econômica.

\section{MATERIAL E MÉTODOS}

O experimento foi conduzido na Faculdade de Ciências Agrárias da Universidade Federal da Grande Dourados, UFGD, no período de março a setembro de 2005, em que se configura a época de cultivo do milho safrinha. O solo utilizado no experimento foi classificado como Latossolo Vermelho Distroférrico Argiloso, relevo suavemente plano (0,5\% de declividade).

A irrigação foi realizada pelo sistema de aspersão convencional, com espaçamento de 12 x 12 m entre linhas e na linha; os aspersores utilizados foram da marca Agropolo (modelo NY 30), com bocais diferentes entre as parcelas, havendo uma parcela sem aspersores, constituindo o tratamento não irrigado (sequeiro).

Tem-se, na Tabela 1, as características avaliadas nos diversos tratamentos para determinação das lâminas de irrigação suplementar.

Obtiveram-se as profundidades do sistema radicular estimadas para a cultura do milho mediante metodologia descrita por Dourado Neto et al. (2000), em que: 0 a $0,15 \mathrm{~cm}$ para o período da emergência, até oito folhas desenvolvidas; 0,15 a $0,30 \mathrm{~cm}$, de oito folhas a doze folhas desenvolvidas e 0,30 a $0,45 \mathrm{~cm}$, quando acima de doze folhas. 
Tabela 1. Características avaliadas durante os testes para lâmina de irrigação suplementar, sendo: Pressão de Serviço (PS); Umidade Relativa (UR); Coeficiente de Uniformidade de Christiansen (CUC) e Precipitação (Ppt)

\begin{tabular}{ccccccc}
\hline Tratamento & $\begin{array}{c}\text { Bocal } \\
(\mathbf{m m} \times \mathbf{~ m m})\end{array}$ & $\begin{array}{c}\text { OS } \\
(\mathbf{m c a})\end{array}$ & $\begin{array}{c}\text { UR } \\
(\mathbf{\%})\end{array}$ & $\begin{array}{c}\text { Vento } \\
\left(\mathbf{m ~ s}^{-1}\right)\end{array}$ & $\begin{array}{c}\text { CUC } \\
(\mathbf{\%})\end{array}$ & $\begin{array}{c}\text { Ppt } \\
\left(\mathbf{m m ~ h}^{-1}\right)\end{array}$ \\
\hline 1 & - & - & - & - & - & - \\
2 & $4,0 \times 4,6$ & 10 & 58 & 1,2 & 89 & 7,8 \\
3 & $5,0 \times 4,6$ & 12 & 63 & 1,3 & 90 & 10,8 \\
4 & $7,1 \times 4,6$ & 10 & 61 & 1,3 & 90 & 18,2 \\
\hline
\end{tabular}

A determinação do coeficiente de uniformidade foi baseada no método de Christiansen (Bernardo, 1995).

O critério utilizado na aplicação da lâmina de irrigação foi feito na análise da curva de retenção de água do solo, no local do experimento (Tabela 2); a umidade do solo foi monitorada por tensiômetros instalados nos tratamentos, nas profundidades de 0,$15 ; 0,30$ e $0,45 \mathrm{~m}$; sempre que o tensiômetro registrasse a tensão de $-0,05 \mathrm{MPa}$ se iniciariam as irrigações, obedecendo as profundidades conforme o desenvolvimento da cultura.

Tabela 2. Água disponível no solo no local do experimento em diversas profundidades

\begin{tabular}{cccccc}
\hline $\begin{array}{c}\text { Profundidade } \\
\text { (cm) }\end{array}$ & $\begin{array}{c}\text { Capacidade } \\
\text { de campo } \\
\text { (\%) }\end{array}$ & $\begin{array}{c}\text { Umidade } \\
\text { crítica }^{1} \\
\mathbf{( \% )}\end{array}$ & $\begin{array}{c}\text { ADSR }^{2} \\
\text { (mm) }\end{array}$ & $\begin{array}{c}\text { Eficiência } \\
\text { da irrigação } \\
\mathbf{( \% )}\end{array}$ & $\begin{array}{c}\text { Lâmina } \\
\text { mínima } \\
\text { (mm) }\end{array}$ \\
$0-15$ & 29,0 & 27,0 & 6,6 & 90 & 7,3 \\
$15-30$ & 32,3 & 29,7 & 8,6 & 90 & 9,5 \\
$30-45$ & 33,4 & 30,4 & 9,9 & 90 & 11,0 \\
\hline
\end{tabular}

1 Umidade critica baseada na tensão de $-0,05 \mathrm{MPa}$, registrada pelos tensiômetros;

2 Água disponível na profundidade do sistema radicular

Em virtude do solo não ter capacidade de armazenar toda a água proveniente de precipitações pluviométricas intensas, ocorrerá percolação das camadas superficiais do solo para camadas mais profundas, ficando disponibilizada para a planta apenas a água disponível no solo, na profundidade do sistema radicular. Conforme ocorre o aprofundamento do sistema radicular, o volume de solo explorado pelas raízes das plantas aumenta; portanto, a lâmina total aplicada no tratamento não irrigado foi somente a precipitação efetiva (água armazenada no solo na faixa do sistema radicular do milho, disponibilizada pelas chuvas) e nos tratamentos irrigados a precipitação efetiva foi somada à irrigação suplementar aplicada em cada tratamento, conforme a Tabela 3.

Os tratamentos, considerando-se a irrigação suplementar, receberam lâminas totais de 360, 410 e 510 mm; o tratamento com lâmina total de $160 \mathrm{~mm}$ caracteriza o tratamento sem irrigação suplementar (sequeiro).

Para melhor entendimento, a irrigação suplementar foi estimada para suprir as perdas por evapotranspiração da cultura, determinada pelo tratamento 4; logo os tratamentos 3 e 2 receberam lâminas correspondentes a aproximadamente 70 e $50 \%$, respectivamente, com base no tratamento 4 .

A estimativa da evapotranspiração de referência foi baseada na metodologia proposta por Penman-Monteith, contida na publicação da FAO 56 (Allen et al., 1998) utilizando-
Tabela 3. Precipitação total ocorrida durante o ciclo da cultura (PTC, $\mathrm{mm})$, precipitação efetiva no período vegetativo (PEPV, mm), precipitação efetiva total no ciclo da cultura (PETC, mm), lâmina suplementar total no ciclo da cultura (LSC, mm) e lâmina total aplicada na cultura (LTA, mm), nos diversos tratamentos utilizados

\begin{tabular}{crrrcc}
\hline \multirow{2}{*}{ Tratamento } & PTC $^{1}$ & PEPV $^{2}$ & PETC $^{3}$ & LSC $^{4}$ & LTA $^{5}$ \\
\cline { 2 - 6 } 1 & & & $(\mathbf{m m})$ & & \\
2 & 292,0 & 70,0 & 160,0 & - & 160,0 \\
3 & 285,0 & 145,0 & 220,0 & 140,0 & 360,0 \\
4 & 285,0 & 145,0 & 220,0 & 190,0 & 410,0 \\
\hline
\end{tabular}

se, para tanto, o programa Reference Evapotranspiration Calculator - REF ET (Allen, 2000); os dados de temperatura, umidade relativa do ar, precipitação, vento e radiação, foram obtidos na Estação Meteorológica da Universidade Federal da Grande Dourados, localizada a 100 m da área do experimento.

Na estimativa da evapotranspiração da cultura utilizaramse os valores médios de kc propostos por Doorenbos \& Kassan (1994), Tabela 4.

Tabela 4. Coeficiente de cultivo $(\mathrm{kc})$ proposto por Doorenbos \& Kassan (1994) para as diversas fases do desenvolvimento da cultura do milho

\begin{tabular}{ccccc}
\hline \multicolumn{5}{c}{ Fases de desenvolvimento da cultura } \\
\hline \multicolumn{5}{c}{ DAE $^{1}$} \\
$0-14$ & $15-35$ & $36-84$ & $85-117$ & $118-134$ \\
0,50 & 0,85 & 1,20 & 0,95 & 0,60 \\
\hline${ }^{1}$ Dias após emergência
\end{tabular}

Calcularam-se os déficits hídricos causados pela evapotranspiração nos diversos estádios de desenvolvimento na cultura do milho, nas diferentes lâminas aplicadas. Quando as diferenças foram positivas, significam que a tensão de água no solo estava na faixa considerada ideal (entre capacidade de campo e umidade crítica), e a evapoanspiração da cultura foi suprida pela irrigação. Considerou-se déficit quando o teor de umidade foi menor que a umidade crítica; quanto mais negativa foi esta diferença maior o estresse hídrico na planta e mais próximo está da tensão correspondente ao ponto de murcha; ressaltar-se que a tensão do ponto de murcha não foi atingida, pois as plantas completaram o seu ciclo com produção de grãos.

Utilizaram-se sementes de milho híbrido triplo de ciclo precoce DG-501, com características de grãos semiduro, amarelo-alaranjado e plantas de porte médio; a semeadura foi realizada em linhas, sucedendo a cultura do feijão, no plantio direto, e as sementes foram colocadas na profundidade de 5 a $7 \mathrm{~cm}$, com espaçamento de $0,90 \mathrm{~m}$ entre linhas e 7 plantas por metro linear correspondendo a aproximadamente 78 mil plantas por hectare, distribuídos no esquema do delineamento inteiramente casualizado, com quatro tratamento e cinco repetições; por fim, a adubação realizada no plantio foi de $350 \mathrm{~kg}$ por hectare de N-P-K na formulação 08-20-20, respectivamente.

Determinou-se a massa seca mediante a coleta de cinco 
plantas por parcela; as plantas foram cortadas junto ao solo, sendo separados folhas e colmos, pesados e levados à estufa, ventilada a $65^{\circ} \mathrm{C}$, até que a massa ficasse constante; avaliou-se, também, o peso de 100 grãos, altura de inserção de espiga e de plantas.

O cálculo de massa de 100 grãos e produtividade foi corrigido para a umidade de $13 \%$; para determinação da produtividade de grãos utilizram-se espigas colhidas em um metro linear, com cinco repetições, realizadas aleatoriamente dentro da parcela.

A fim de estimar a área foliar, lançou-se mão de um integrador fotoelétrico e, com base nas características fisiológicas avaliadas, se ajustaram equações de regressão em função das diferentes lâminas aplicadas considerando-se os seguintes índices produtivos na maturidade fisiológica (colheita): área foliar, altura de inserção da espiga, altura de planta, massa seca da espiga, massa seca total e peso de 100 grãos.

Na classificação dos estádios de desenvolvimento da cultura do milho se utilizaram os parâmetros de Fancelli (1991), conforme a Tabela 5.

Tabela 5. Estádios de desenvolvimento do milho, de acordo com a classificação fisiológica de Fancelli (1991)

\begin{tabular}{lcl}
\hline Período & Estádio & Classificação fisiológica \\
Vegetativo & 1 & Planta com 4 folhas desdobradas \\
& 2 & Planta com 8 folhas \\
3 & Plantas com 12 folhas \\
4 & Emissão do pendão \\
\hline & 5 & Flor-escimento e polinização \\
& 6 & Grãos leitosos \\
Reprodutivo & 7 & Grão pastoso \\
& 8 & Aparecimento de concavidade no grão \\
& 9 & Grãos duros \\
& 10 & Grãos duros fisiologicamente \\
\hline
\end{tabular}

Utilizaram-se, no cálculo de viabilidade econômica, os índices financeiros para o custo de produção do milho safrinha de 2005, divulgado pelo Banco do Brasil (2005), e as tarifas de energia homologadas na ANEEL $n^{\circ} 74$, fornecidas pela ENERSUL-S/A (2005).

Para a capacidade de pagamento do conjunto irrigação, empregou-se um valor fixo da ordem de $\mathrm{R} \$ 4.500,00$ por hectare, com base no custo médio da irrigação na região de Dourados, MS, conforme consulta ao comércio local, e se calculou uma vida útil para o equipamento de 15 anos, com ajuste na depreciação de $13,0 \%$ ao ano.

No cálculo da depreciação anual do equipamento foi empregada a seguinte equação:

$$
\mathrm{DE}=\frac{\mathrm{VCI} \times \mathrm{DA}}{\mathrm{VU} \times 100}
$$

em que:

DE - depreciação anual, R\$ ano

VCI - valor do conjunto de irrigação, R\$

DA - depreciação anual, \%

VU - vida útil do equipamento, anos
Calculou-se o custo por safra através da depreciação anual dividido pelo número de dias total do ciclo da cultura e, para o cálculo do custo de energia e se considerando a tarifa normal, utilizou-se a expressão:

$$
\mathrm{TN}=\mathrm{Pm} \times 0,736 \mathrm{P}
$$

em que:

$$
\begin{aligned}
& \mathrm{TN} \text { - tarifa normal, } \mathrm{kW} \mathrm{h}^{-1} \\
& \mathrm{Pm} \text { - potência do motor, cV } \\
& \mathrm{P} \text { - preço do } \mathrm{kW}, \mathrm{R} \$
\end{aligned}
$$

O cálculo da tarifa de irrigante foi dado pela equação:

$$
\mathrm{TI}=\frac{\mathrm{TN} \cdot \mathrm{D}}{100}
$$

em que:

$$
\begin{aligned}
& \text { TI - tarifa do irrigante, h } \\
& \text { TN - tarifa normal, R\$ } \\
& \text { D - desconto, \% }
\end{aligned}
$$

O custo da lâmina aplicada foi calculado pela equação:

$$
\mathrm{CLA}=\left(\frac{(\mathrm{HI} \times \mathrm{TI})+(\mathrm{HN} \times \mathrm{TN})}{\mathrm{LDA}}\right)+\left(\frac{\mathrm{DM} \times 0,736 \mathrm{Pm}}{\mathrm{NDM} \times \mathrm{LDA}}\right)
$$

em que:

CLA - custo da lâmina aplicada, R\$ mm

HI - horas de aplicação no horário de irrigação com desconto, $\mathrm{h}$

HN - horas de aplicação no horário normal, h

LDA - lâmina diária aplicada, mm

$\mathrm{DM}$ - demanda do motor, $\mathrm{kW}$

NDM - número de dias do mês

Com vistas à produtividade máxima, realizou-se uma simulação empregando-se o modelo obtido pela equação de regressão ajustada, dada pela produtividade do milho safrinha em função das lâminas aplicadas.

A determinação do custo de produção, como preparo do solo, plantio, tratos culturais e colheita, foi considerada igual para todos os tratamentos.

Os componentes dos custos fixos utilizados no cálculo de viabilidade econômica, foram: semente, defensivos, serviços no plantio, tratos culturais, colheita (inclusos a mão-de-obra e o custo da hora/máquina). Nos custos variáveis foram utilizados o custo por safra do equipamento (inclusa a depreciação do equipamento) e o consumo de energia.

O valor utilizado para o quilograma do milho foi de R\$ 0,2408.

\section{RESULTADOS E DISCUSSÃO}

A Tabela 6 apresenta a diferença entre os saldos da evapotranspiração acumulada e lâminas de irrigação aplicadas nos diversos estádios de desenvolvimento em todos os tratamentos. Observa-se que, nas fases iniciais 1 a 3 (semeadura até atingir 12 folhas) no tratamento não, houve grande período de estiagem, fazendo com que a planta sofresse maior 
estresse hídrico, vez que a umidade proveniente da precipitação pluvial não foi suficiente para neutralizar essa diferença; seu desenvolvimento foi restrito a tensões de umidade abaixo da umidade crítica. Nos tratamentos em que receberam lâminas de irrigação suplementar, as diferenças foram positivas em quase todos os estádios da cultura; no tratamento irrigado com lâmina de 510 mm não houve diferenças negativas nas diferentes fases do desenvolvimento da planta; na aplicação da lâmina total de 360 mm ocorreu déficit hídrico, tanto na fase vegetativa (estádio de 4 para 8 folhas) como na reprodutiva (emissão do pendão) e no tratamento com lâmina total de 410 mm, não ocorreu estresse hídrico, com exceção do estádio 4 (emissão do pendão), considerado período crítico da cultura, com déficit da ordem 0,2 mm.

Tabela 6. Déficits hídricos causados pela evapotranspiração nos diversos estádios de desenvolvimento na cultura do milho, nas diferentes lâminas aplicadas

\begin{tabular}{ccccc}
\hline \multirow{2}{*}{ Estádio } & \multicolumn{5}{c}{ Lâminas $(\mathrm{mm})$} \\
\cline { 2 - 5 } 1 & $\mathbf{1 6 0}$ & $\mathbf{3 6 0}$ & $\mathbf{4 1 0}$ & $\mathbf{5 1 0}$ \\
2 & -38 & + & + & + \\
3 & -40 & -15 & + & + \\
4 & -53 & + & + & + \\
5 & -12 & -10 & $-0,2$ & + \\
6 & -9 & + & + & + \\
6 & -12 & + & + & + \\
7 & -20 & + & + & + \\
8 & -32 & + & + & + \\
9 & -43 & + & + & + \\
\hline
\end{tabular}

A Figura 1 representa a variação temporal da precipitação, evapotranspiração acumulada da cultura nos tratamentos sem e com irrigação suplementar. O tratamento sem irrigação suplementar (Figura 1A) apresentou redução no stand, provavelmente pela demora da emergência das plântulas em 40 dias após a semeadura em relação aos tratamentos irrigados; este fato pode ser explicado em razão da baixa precipitação na fase inicial de desenvolvimento da cultura, levando ao retardamento da colheita quanto aos tratamentos que receberam irrigação suplementar; conclui-se, com isto ser possível afirmar que o sucesso no cultivo do milho safrinha depende, fundamentalmente, da ocorrência de condições climáticas adequadas por ocasião da semeadura, ou seja, se os elementos climáticos apresentarem grande variabilidade espacial e temporal na fase inicial, devido à ocorrência de períodos prolongados de veranicos, a produtividade da cultura será afetada negativamente.

A possibilidade de geadas durante a fase de florescimento caracteriza outro problema no cultivo do milho safrinha devido ao risco de perda da safra. Apesar de se constituir importante fator de risco na região Sul de Mato Grosso do Sul, neste trabalho não houve geadas durante o experimento, em que a temperatura média do ar foi de $24,9^{\circ} \mathrm{C}$, máxima de $33,8^{\circ} \mathrm{C}$ e mínima de $16,5^{\circ} \mathrm{C}$.

Na fase reprodutiva, considerada período crítico por diversos autores (EMBRAPA, 1993), o tratamento não irriga- do (Figura 1A) apresentou um período menor entre o estádio de 12 folhas até o florescimento (13 dias), enquanto nos tratamentos com irrigação suplementar (Figuras 1B, 2A e 2B) esse período foi maior (27 dias), fato que pode ser explicado pela própria característica fisiológica natural da planta, pois quando a planta está em condições de estresse e ainda desenvolver seus órgãos reprodutivos, o faz rapidamente a fim de manter a perpetuação da espécie.

O suprimento de água para a cultura por meio das chuvas no estádio reprodutivo garantiu ao tratamento não irrigado uma produtividade no milho safrinha, mesmo com períodos de estiagem no início do ciclo da cultura; logo, embora em anos de estiagem, a cultura poderá apresentar produção, contanto que haja suprimento hídrico mínimo nos períodos críticos; portanto, a irrigação na cultura do milho safrinha antes de representar aplicação de grande quantidade de água, significa atender às necessidades hídricas mínimas para o desenvolvimento da cultura.

Os tratamentos irrigados, e apesar de terem sido aplicadas lâminas diferentes (360, 410 e 510 mm), apresentaram comportamentos semelhantes quanto ao seu desenvolvimento, com duração dos estádios iguais (Figuras 1B, 2A e 2B).

A quantidade de água necessária para emergência da planta na fase inicial, não foi elevada, pois com apenas $6,0 \mathrm{~mm}$, evidenciado no tratamento com irrigação suplementar de 360 mm (Figura 1B), foi suficiente para a emergência; este fato é relevante em pequenas propriedades principalmente naquelas com restrições quanto a mananciais ou equipamento disponível.

Para todas as características fisiológicas avaliadas na maturidade fisiológica, (Figura 3), a análise estatística mostrou-se significativa pelo teste "F" a 5\% de probabilidade, evidenciando aumentos lineares das características fisiológicas avaliadas com incremento da irrigação suplementar.

Na Figura 3A se observou aumento da área foliar sempre que ocorreu incremento da lâmina aplicada. A área foliar é importante, haja vista que as folhas são as principais responsáveis pela captação de energia solar para a produção de fotoassimilados, por meio da fotossíntese.

As relações entre o estresse hídrico e o desenvolvimento dos vegetais são muito complexas, dado ao elevado número de processos fisiológicos envolvidos, que são afetados de modos e intensidades diferentes com relação à disponibilidade de água no solo entretanto, a menor disponibilidade de água atua direta e fisicamente, reduzindo o crescimento das plantas pela diminuição da turgescência celular, exercendo efeito negativo, sobretudo na fase inicial da expansão celular; portanto, há intensa redução da taxa de crescimento da área foliar que se constitui em um dos primeiros sintomas da deficiência hídrica na planta.

As maiores alturas de inserção das espigas (Figura 3B) e da planta (Figura 3C) poderão predispor a planta ao acamamento ou quebramento, fatores que não ocorreram durante o período de realização do experimento, provavelmente pelo fato do híbrido utilizado não ser suscetível a essas características indesejáveis; no entanto, é necessário se ter cautela com outras variedades já que o sistema radicular se aprofunda menos em lâminas maiores. 


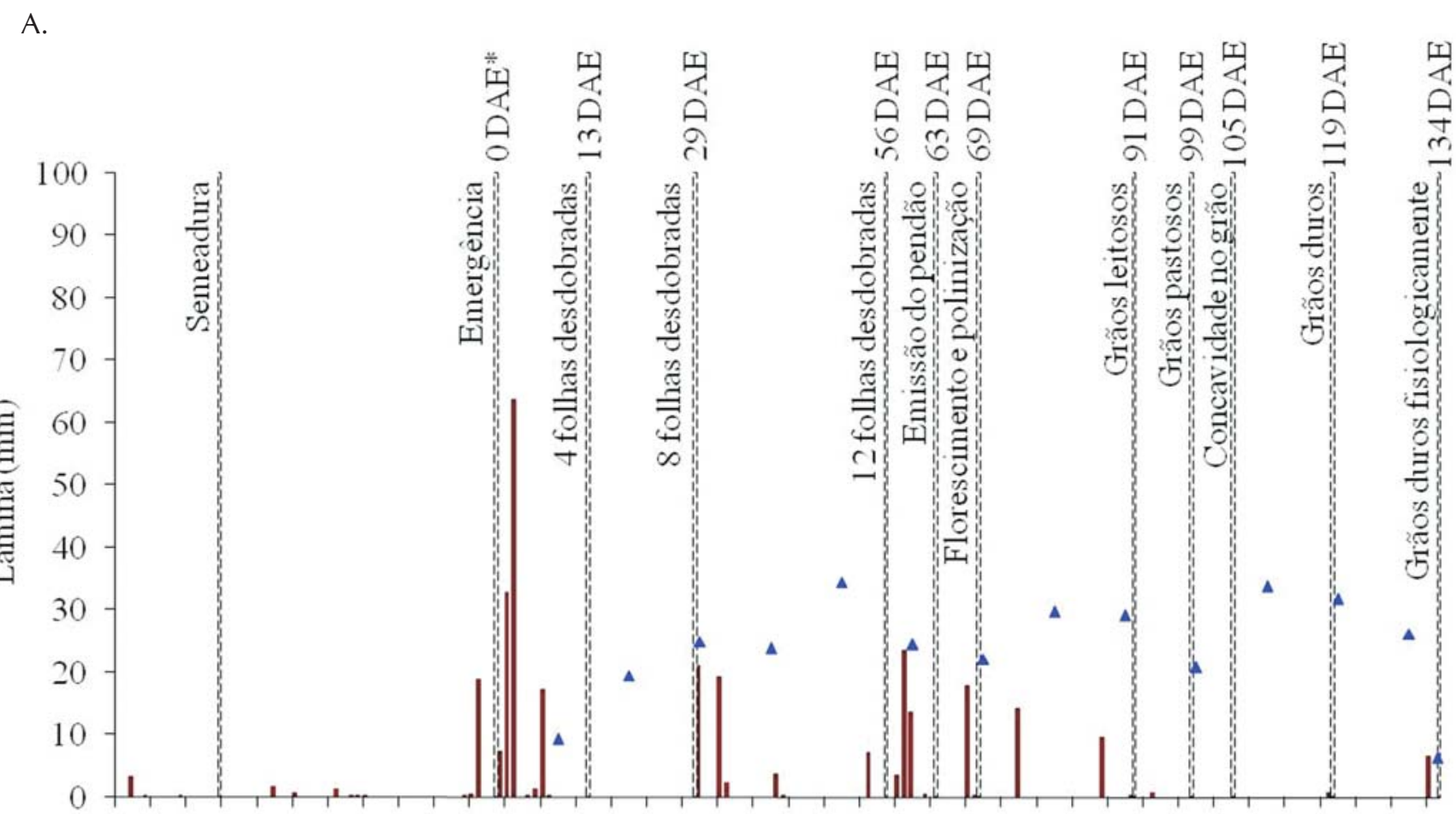

1/mar 16/mar 31/mar 15/abr 30/abr 15/mai 30/mai 14/jun 29/jun 14/jul 29/jul 13/ago 28/ago

B.

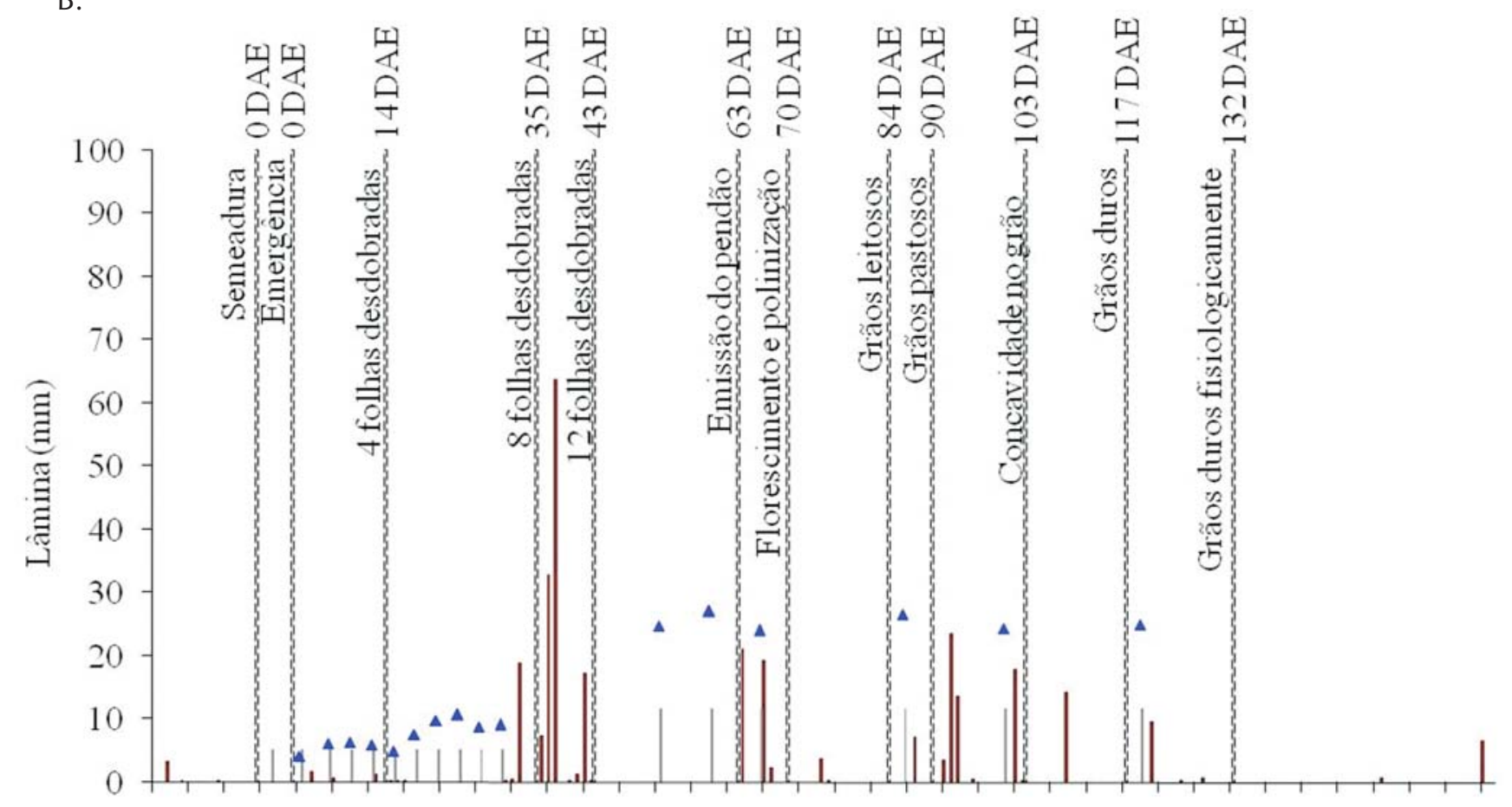

1/mar 16/mar 31/mar 15/abr 30/abr 15/mai 30/mai 14/jun 29/jun 14/jul 29/jul 13/ago 28/ago Periodo (dias) 
A.

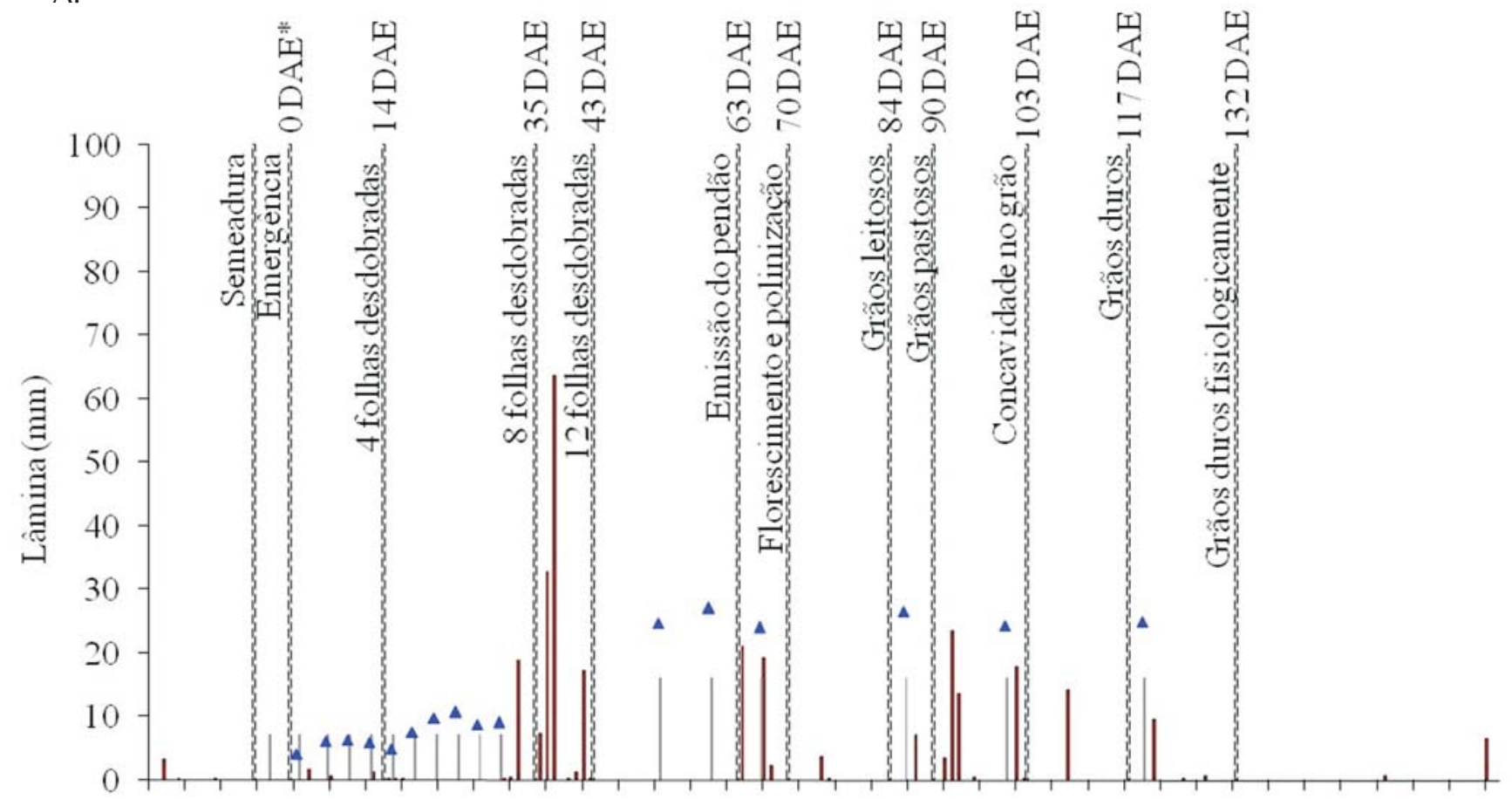

1/mar 16/mar 31/mar 15/abr 30/abr 15/mai 30/mai 14/jun 29/jun 14/jul 29/jul 13/ago 28/ago

B.

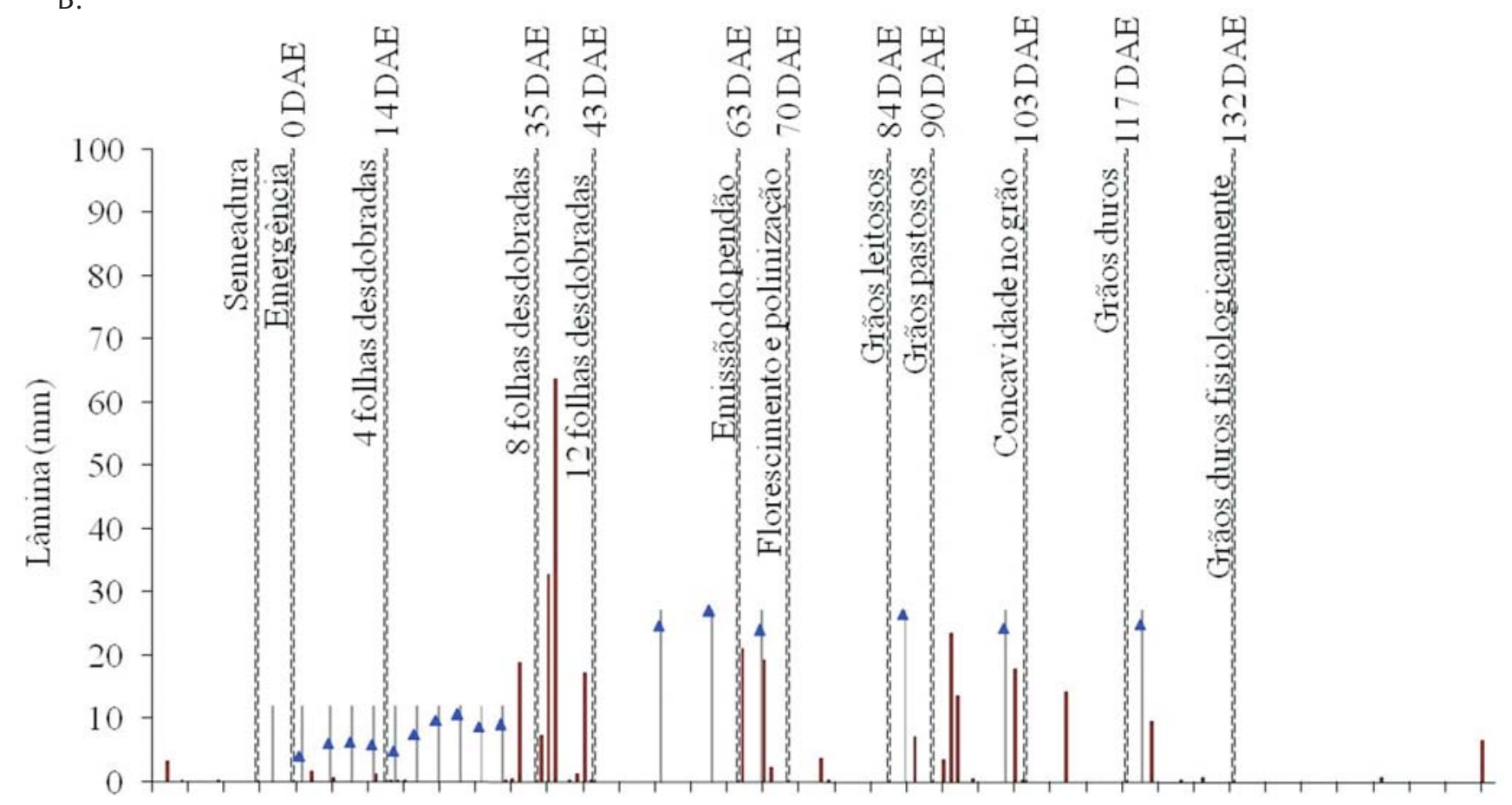

1/mar 16/mar 31/mar 15/abr 30/abr 15/mai 30/mai 14/jun 29/jun 14/jul 29/jul 13/ago 28/ago Periodo (dias)

- Precipitação diária

* Irrigação suplementar

$\triangle \mathrm{ETc}$

* Dias após emergência

Figura 2. Variação temporal da precipitação e evapotranspiração acumulada da cultura nos tratamentos com irrigação suplementar, sendo: (A) lâmina total de $410 \mathrm{~mm}$ e (B) lâmina total de $510 \mathrm{~mm}$ 
A.

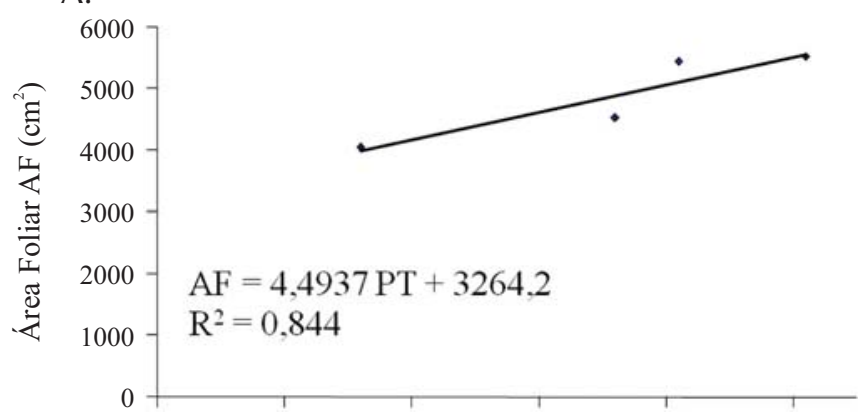

C.

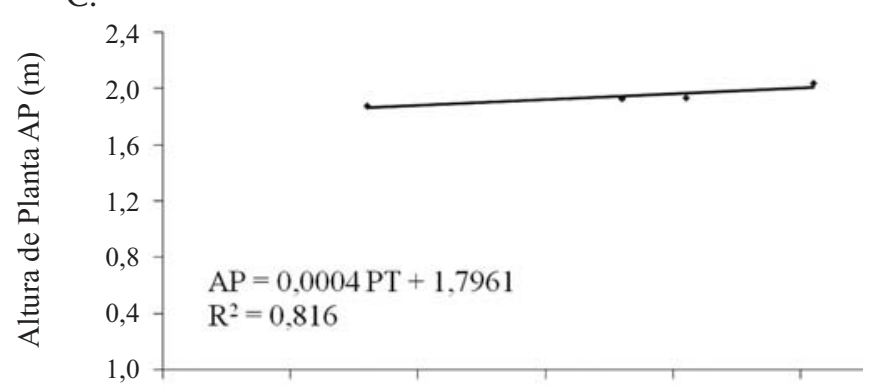

E.

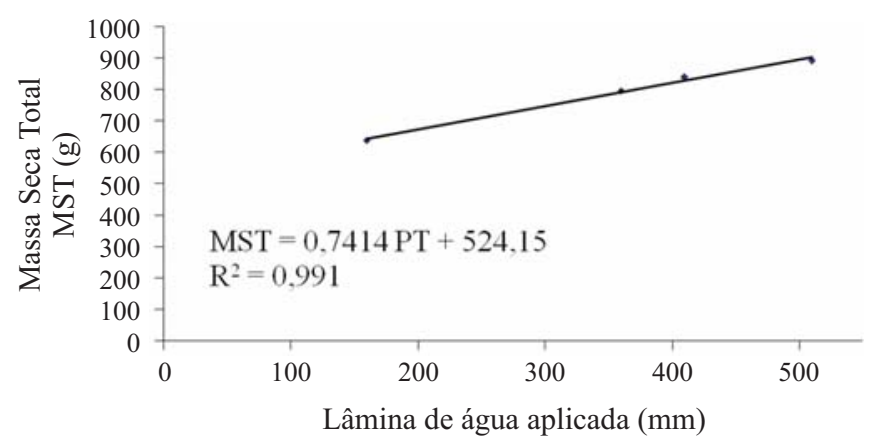

B.

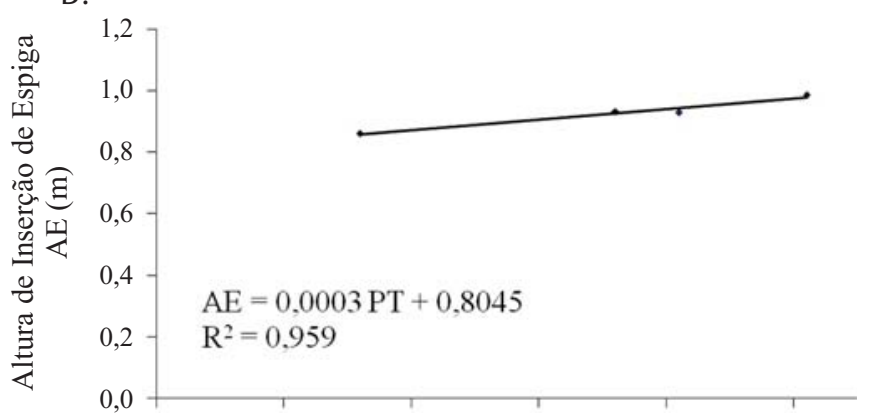

D.

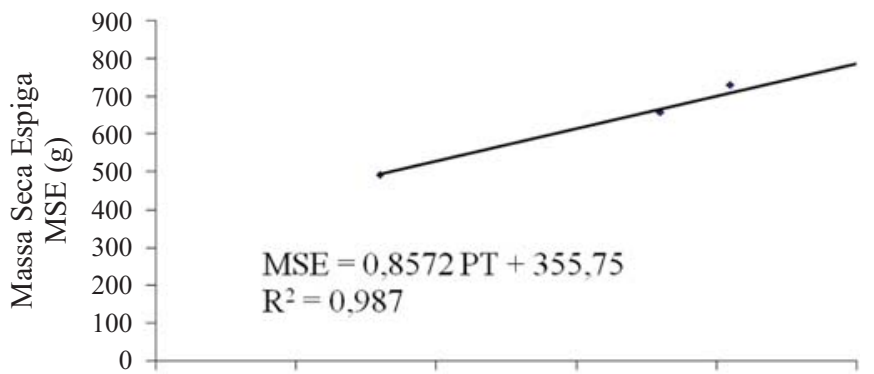

F.

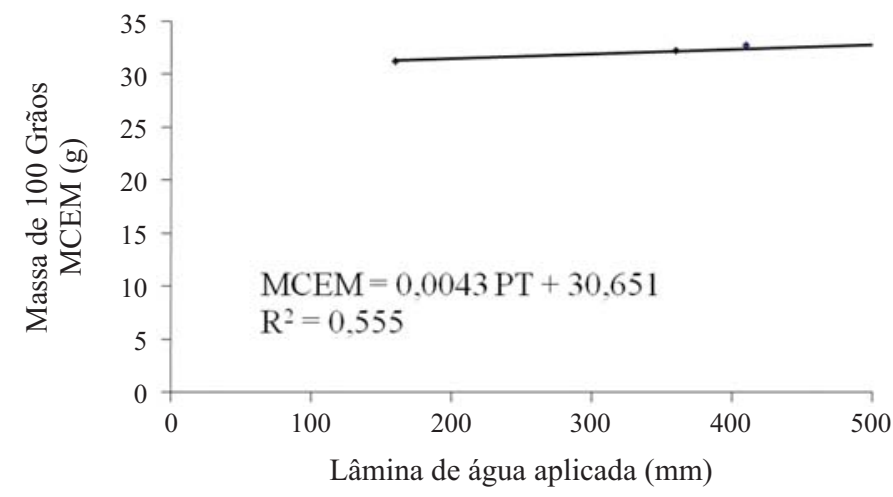

Figura 3. Características fisiológicas avaliadas na cultura do milho safrinha sob diferentes lâminas de água aplicadas, considerando-se o estádio de maturidade fisiológica, referente a: (A) área foliar; (B) altura da inserção de espiga; (C) altura da planta; (D) massa seca da espiga; (E) matéria seca total da parte aérea e (F) massa de 100 grãos

Com relação à massa seca da espiga (Figura 3D), os menores teores foram encontrados nos tratamentos nos quais as plantas sofreram maior deficiência hídrica, comportamento que pode ser também atribuído à diminuição da área foliar no período vegetativo. Um dos fatores para a diminuição da massa seca está relacionado aos déficits hídricos das plantas as quais podem apresentar insuficiência de assimilados para manter o crescimento de todos os zigotos formados, além de mostrarem, também, redução no tempo da polinização, pela inibição do alongamento do estilete e retardamento na emergência dos estigmas; outro fator é que o desenvolvimento e o peso dos grãos podem ser afetados pela redução da fotossíntese, pois a menor produção de carboidratos implica em menor quantidade de matéria seca nos grãos, razão por que os tratamentos com lâminas menores não tiveram bons resultados.

O acúmulo de massa seca vegetal (Figura 3E) é o resultado do mecanismo fotossintético, o qual sintetiza fotoassimilados na planta; logo, todo e qualquer fator que interfira na fotossíntese afetará, sem dúvida, o acúmulo de matéria seca. Fatores como nutrição mineral, radiação e disponibilidade hídrica interferem, expressivamente, na fotossíntese e, dentre esses, a disponibilidade de água desempenha papel preponderante uma vez que, além de propiciar a entrada de $\mathrm{CO}_{2}$, promove o resfriamento do vegetal, interferindo na taxa de fotossíntese e de respiração, aumentando a massa seca com o aumento da lâmina aplicada.

Verifica-se, na Figura 3F, redução da massa de 100 grãos com a diminuição da lâmina de água aplicada; este componente foi afetado pela manutenção da condição restritiva de água às plantas na época de granação, que pode ter afetado o enchimento de grãos; referidos resultados estão de acordo com os obtidos pela EMBRAPA (1993), relatando que a deficiência hídrica no período vegetativo e reprodutivo diminui o crescimento dos grãos pela menor disponibilidade de $\mathrm{CO}_{2}$, limitando os processos de elongação celular.

A Figura 4 apresenta a produtividade da cultura do milho safrinha sob diferentes lâminas de água aplicadas. 
Observa-se, apesar do híbrido triplo DG-501 ser de boa estabilidade de produção, que a produtividade foi diretamente afetada pelas condições hídricas do solo, sendo significativa nos diferentes tratamentos utilizados. A equação ajustada apresentou função quadrática com o ponto de máximo de $6.975 \mathrm{~kg} \mathrm{ha}^{-1}$ e lâmina de $608 \mathrm{~mm}$.

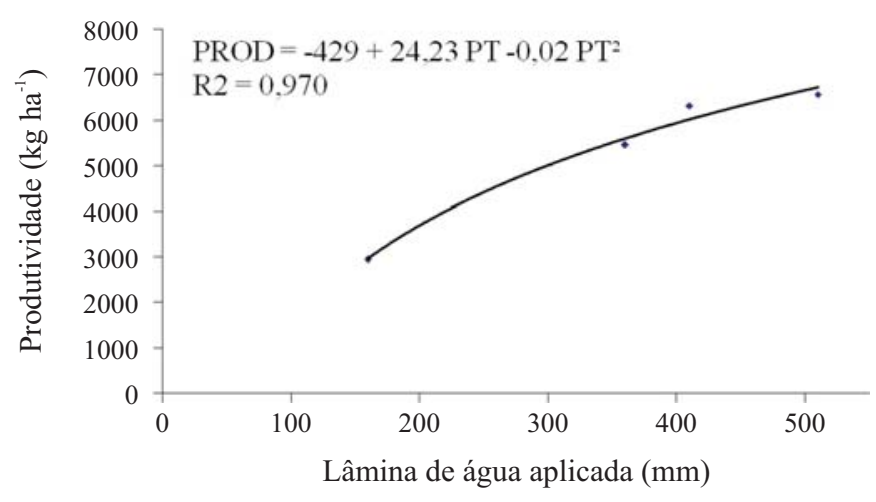

Figura 4. Produtividade do milho safrinha sob diferentes lâminas de água

O tratamento com lâmina de $410 \mathrm{~mm}$ acarretou um pequeno déficit hídrico no estádio de emissão do pendão (estádio 4), considerado período crítico da cultura, conforme já discutido. Este fato levou à perda de produtividade em 6,75\% quando comparado com o tratamento com irrigação suplementar de $510 \mathrm{~mm}$. Nota-se que a cultura é muito sensível ao déficit hídrico durante as fases fenológicas de florescimento e início da formação de grãos.

No tratamento não irrigado, mesmo com déficit hídrico causado pela evapotranspiração em todos os estádios, obteve-se produtividade normal para a região de Dourados, MS (2.750 kg ha-1), em condições de sequeiro.

O tratamento com maior lâmina aplicada $(510 \mathrm{~mm})$ aumentou a produtividade em aproximadamente $130 \%$ com relação ao tratamento não irrigado. O efeito da limitação de água sobre o rendimento do milho em grãos é considerável, sendo imprescindível o controle cuidadoso da freqüência e da lâmina de irrigação para se obter rendimentos ótimos em condições de escassez de água; portanto, onde o suprimento de água for limitado poderá ser mais vantajoso atender a todas as necessidades hídricas da cultura para se obter rendimento próximo do máximo com uma área limitada, ao invés de se aplicar pouca água, não suprindo as necessidades hídricas da planta, em uma área maior.

O valor estimado do custo de produção de um hectare de milho de sequeiro foi da ordem de R $\$ 607,8$ (Tabelas 7), muito próximo da renda bruta, estimada em $\mathrm{R} \$ 713,30$ por hectare, tornando o sistema de milho safrinha sem irrigação com pouca rentabilidade, a não ser que a cultura seja vista como "cultura chave" em um sistema de rotação de culturas, em que os benefícios devem ser sinérgicos com outras culturas.

O custo de energia da irrigação suplementar por lâmina aplicada foi de R\$ 0,36. Quando se utilizou a irrigação suplementar a renda líquida por hectare foi maior que o tratamento não irrigado (Tabela 7), tornando o manejo de irrigação no milho safrinha, rentável economicamente.

Por meio da simulação realizada com a equação de regressão ajustada para produtividade em função da lâmina aplicada (Eq. 5), observou-se que a maior produtividade para o milho safrinha não se transformou em maior renda líquida, em virtude do custo de energia ter aumentado substancialmente, para aplicar a lâmina necessária (608 mm). A maior renda líquida encontrada (R\$ 837,89) correspondeu à lâmina de 570 mm; ressalta-se, entretanto, que esses valores servem apenas como referência para operacionalizar o modelo de análise proposto, visto que os resultados são sensíveis aos dados de custo e ao preço de venda do produto e, ainda, cada análise deve retratar as peculiaridades inerentes à lavoura focalizada.

$$
\mathrm{PROD}=-424+24,33 \mathrm{PT}-0,02 \mathrm{PT}^{2}
$$

em que:

$$
\begin{array}{r}
\text { PROD - produtividade, } \mathrm{kg} \mathrm{ha}^{-1} \\
\text { PT - precipitação total, mm }
\end{array}
$$

\begin{tabular}{|c|c|c|c|c|c|c|}
\hline Tratamentos & L (160) & $L(360)$ & L (410) & L (510) & $\mathrm{L}(608)^{\star}$ & $L(570)^{\star *}$ \\
\hline Produtividade Média Kg ha-1 & 2.961 & 5.642 & 6.380 & 6.842 & 6.975 & 6.99 \\
\hline Custo de preparo de solo/plantio & $\mathrm{R} \$ \mathrm{ha}^{-1}$ & $\mathrm{R} \$ \mathrm{ha}^{-1}$ & $\mathrm{R} \$ \mathrm{ha}^{-1}$ & $\mathrm{R} \$ \mathrm{ha}^{-1}$ & $\mathrm{R} \$ \mathrm{ha}^{-1}$ & $\mathrm{R} \$ \mathrm{ha}^{-1}$ \\
\hline Fertilizantes & 149,58 & 149,58 & 149,58 & 149,58 & 149,58 & 149,58 \\
\hline Semente & 85 & 85 & 85 & 85 & 85 & 85 \\
\hline Defensivos & 34,75 & 34,75 & 34,75 & 34,75 & 34,75 & 34,75 \\
\hline Serviços & 70,94 & 70,94 & 70,94 & 70,94 & 70,94 & 70,94 \\
\hline \multicolumn{7}{|l|}{ Tratos Culturais } \\
\hline Defensivos & 40,45 & 40,45 & 40,45 & 40,45 & 40,45 & 40,45 \\
\hline Serviços & 31,1 & 31,1 & 31,1 & 31,1 & 31,1 & 31,1 \\
\hline \multicolumn{7}{|l|}{ Colheita } \\
\hline Serviços & 196 & 196 & 196 & 196 & 196 & 196 \\
\hline Equipamento de Irrigação & 0 & 125 & 125 & 125 & 125 & 125 \\
\hline Energia & 0 & 26,25 & 43,75 & 78,75 & 113,05 & 102,6 \\
\hline Total de Despesas por ha & 607,82 & 759,07 & 776,57 & 811,57 & 845,87 & 835,42 \\
\hline Renda Bruta & 713,3 & $1.359,16$ & $1.536,94$ & $1.648,24$ & $1.680,36$ & $1.673,31$ \\
\hline Renda Líquida & 105,48 & 600,09 & 760,37 & 836,67 & 834,49 & 837,89 \\
\hline
\end{tabular}

Tabela 7. Viabilidade econômica de diferentes lâminas de irrigação para o milho safrinha, em R\$ por hectare (2005)

* Maior produtividade; ** Maior renda líquida 


\section{CONCLUSÕES}

1. Houve incremento na produtividade com maiores lâminas de água.

2. O acúmulo de massa seca dos componentes de produção foi linear com lâminas de irrigação aplicada.

3. O déficit hídrico nos períodos críticos diminuiu a produtividade.

4. A irrigação suplementar foi viável economicamente para o milho safrinha;

5. A maior produtividade para o milho safrinha não se transformou em maior renda líquida.

\section{LITERATURA CITADA}

Aldrich, S. R.; Scott, W. O.; Leng, R. E. Modern corn production. 2.ed. Champaign: A \& L Publication, 1982. 371p.

Allen, R. G. Reference evapotranpiration calculator. Idaho: University of Idaho Research and Extension Center Kimberly, 2000, 75p.

Allen, R. G.; Pereira, L. S.; Raes, D.; Smith, M. Grop evapotranspiration: Guidelines for computing crop water requirements. FAO irrigation and drainage. Rome: Food and Agriculture Organization of the United Nations, 1998. 328p.

Banco do Brasil. Planilha de custos do milho safrinha para cálculo de viabilidade econômica na região Centro-oeste. Banco do Brasil, 2005.

Bernardo, S. Manual de Irrigação. 6.ed. Viçosa: UFV, 1995. 657p.

Bernardo, S. Impacto ambiental da irrigação no Brasil. Recursos hídricos e desenvolvimento sustentável da agricultura. Viçosa: MMA, SRH, ABEAS, UFV, 1997. 252p.

CONAB - Companhia Nacional de Abastecimento. Safra do milho safrinha. <http://www.conab.org.br>. 28 Dez. 2005.
Cunha, G. R.; Bergamaschi, H. Efeito da disponibilidade hídrica sobre o rendimento das culturas. Porto Alegre: UFRGS, 1992. p.85-97.

Doorenbos, J.; Kassam, A. H. Efeito da água no rendimento das culturas. Campina Grande: UFPB, 1994. 306p. Estudos FAO. Irrigação e Drenagem, 33

Dourado Neto, D. D.; Garcia, A. G.; Oliveira, O. J. Modelo cosenoidal referente à curva de crescimento do sistema radicular da cultura de milho (zea mays l.) sob irrigação em condições de campo. Ciência Agrotécnica, v.24 (ed. Especial), p.197-204, 2000.

EMBRAPA - Empresa Brasileira de Pesquisa Agropecuária. Recomendações técnicas para o cultivo do milho. Brasília: Embrapa - Milho, 1993. 204p.

ENERSUL S/A. Agência Nacional de Energia Elétrica - ANEEL. Resolução Homologatória no 74, de 06 de Abril de 2005.

Fancelli, A. L. Milho e feijão: Elementos de manejo em agricultura irrigada. Fertirrigação: Algumas considerações. Piracicaba: ESALQ, 1991. p.156-167.

Goedert, W. J.; Lobato, E.; Wagner, E. Potencial agrícola da região dos cerrados brasileiros. Pesquisa Agropecuária Brasileira, v.15, n.1, p.1-17, 1980.

Henckel, P. A. Physiology of plants under drought. Annual Review of Plant Physiology, v.15, p.363-86, 1964.

Lopes, A. S. Solos sob cerrado: Características, propriedades e manejo. Piracicaba: Instituto da Potassa \& Fosfato, 1983. 162p.

Resende, M.; França,G. E.; Couto, L. Cultura do milho irrigado. Sete Lagoas: Embrapa CNPMS, 2000. 39p.

Shaw, R. H. Corn and corn improvement. Madison: American Society of Agronomy, 1977. p.599-617.

Tsunechiro, A.; Miele Jr., C. Análise de risco de produção e do mercado da milho safrinha. In: Seminário sobre a Cultura do Milho "Safrinha", 5, 1999, Barretos. Anais... Campinas: Instituto Agronômico, 1999. p.127-132. 